\title{
Production and purification of staphylococcal nuclease in Lactococcus lactis using a new expression-secretion system and a pH-regulated mini-reactor
}

\author{
Nicolas Trémillon¹,2, Nicolas Issaly1, Julien Mozo1, Thomas Duvignau1', Hervé Ginisty*1, Eric Devic and \\ Isabelle Poquet ${ }^{2}$
}

\begin{abstract}
Background: Staphylococcal (or micrococcal) nuclease or thermonuclease (SNase or Nuc) is a naturally-secreted nucleic acid degrading enzyme that participates in Staphylococcus aureus spread in the infected host. Purified Nuc protein can be used as an exogenous reagent to clear cellular extracts and improve protein purification. Here, a recombinant form of Nuc was produced and secreted in a Gram-positive host, Lactococcus lactis, and purified from the culture medium.

Results: The gene segment corresponding to the S. aureus nuclease without its signal peptide was cloned in an expression-secretion vector. It was then fused to a lactococcal sequence encoding a signal peptide, and expressed under the control of a lactococcal promoter that is inducible by zinc starvation. An L. lactis subsp cremoris model strain (MG1363) transformed with the resulting plasmid was grown in either of two media (GM17v and CDM) that are free of animal compounds, allowing GMP (Good Manufacturing Practice) production. Induction conditions (concentration of the metal chelator EDTA and timing of addition) in small-scale pH-regulated fermentors were optimized using LacMF (Lactis Multi-Fermentor), a home-made parallel fermentation control system able to monitor 12 reactors simultaneously. Large amounts of recombinant Nuc (rNuc) were produced and secreted in both media, and rNuc was purified from GM17v medium in a single-step procedure.

Conclusions: In L. lactis, rNuc production and secretion were optimal after induction by $0.5 \mathrm{mM}$ EDTA in small scale $\left(200 \mathrm{~mL}\right.$ ) GM17v exponential phase cultures (at an $\mathrm{OD}_{600}$ of 2), leading to a maximal protein yield of $210 \mathrm{mg}$ per $\mathrm{L}$ of culture medium. Purified rNuc was highly active, displaying a specific activity of $2000 \mathrm{U} / \mathrm{mg}$.
\end{abstract}

\section{Background}

L. lactis which is widely used as a starter in dairy industries, is also an efficient cell factory for the production and secretion of proteins [1]. i) Proteins produced in this species, which is considered as safe by virtue of its longtime human consumption, should obtain the GRAS (Generally Recognized As Safe) status and be suitable for therapeutical or vaccine applications [1], in contrast to proteins produced in Escherichia coli from which endotoxin (LPS) has to be removed [2]. ii) In this $\mathrm{Gram}^{+}$spe-

\footnotetext{
* Correspondence: ginisty@gtptech.com

1 GTP-Technology, Immeuble Biostep, BP 48184, 31681 Labège Cedex, France Full list of author information is available at the end of the article
}

cies, the secretion of any heterologous protein fused to an appropriate signal peptide can be easily and efficiently driven by the general export (Sec) pathway [1], thus avoiding potential intra-cellular toxicity and/or misfolding. iii) In this species, an extracellular protease-free strain (without the unique surface protease HtrA [3]) is a useful host to avoid protein degradation [4], whereas in Bacillus subtilis, not all extracellular proteases have been inactivated to date (4 active surface proteases, including the 3 HtrA family members, are remaining in the available mutant strains) [5,6]. iv) Only one major protein, Usp45, is secreted in significant amounts into the medium [7], thus facilitating downstream purification 
steps. v) Finally, setting up conditions for protein production in large fermentors should be easy as culture scaleup is linear [8].

In this context, several gene expression systems have been developed for L. lactis: i) NICE, the most widely used system based on the $\mathrm{P}_{\text {nis }}$ promoter and nisRK twocomponent regulatory system, is induced by nisin [9]; ii) $\mathrm{P} 170$, which is regulated by $\mathrm{RcFB}$, is induced by lactic acid, in particular during the transition to the stationary phase of growth where the $\mathrm{pH}$ is low due to lactate accumulation $[10,11]$ (SM Madsen, personal communication), and iii) $\mathrm{P}_{\mathrm{Zn}}$ is tightly regulated by the ZitR repressor in response to extra-cellular $\mathrm{Zn}^{2+}$ levels: it is repressed in a wide concentration range from repletion to toxicity, and induced by starvation [12-14] (Daniel Llull, Olivier Son, Nicolas Trémillon, Sandrine Blanié, Julien Briffotaux, Sébastien Blugeon, Eric Morello, Hélène Rogniaux, Olivier Danot, and Isabelle Poquet: ZitR, a prototype of a new class of zinc responsive repressors in Streptococcaceae, submitted). As an expression system, ZitR-regulated $\mathrm{P}_{\mathrm{Zn}}$ should allow the repression of a potentially toxic heterologous ORF in the presence of $\mathrm{Zn}^{2+}$ (e. g. in a rich medium), and once a sufficient amount of biomass has been obtained, its induction by addition of a chelator agent (e. g. EDTA) $[12,14]$. To allow protein secretion, expression systems have been combined with several signal peptides: i) that of Usp45 [1,7] ii) that of Exp4 $[13,15,16]$, and iii) several optimized signal peptides (SP310 series) $[17,18]$.

Finally, with the use of all available tools, L. lactis has proved to be an efficient host for the production and secretion of proteins of medical interest, generally in flasks for laboratory studies [1], but also in small scale (1L) fermentors [17]. Recently, the lysostaphin from Staphylococcus simulans biovar staphylolyticus was successfully produced at the industrial scale $(3000 \mathrm{~L})$ in $L$. lactis using the NICE system. Surprisingly though, this naturally-secreted protein was produced as a recombinant signal peptide-free form that had to be purified from the lactococcal cell extract $[8,19]$.

In the present study, the efficiency of L. lactis as a host for heterologous protein production and secretion, and the ease of protein purification from a lactococcal culture medium were evaluated using the staphylococcal nuclease Nuc $[20,21]$ as a model protein of biotechnological and commercial interest. Nuc is a robust exo- and endo5'-phosphodiesterase (EC 3.1.31.1) active against both DNA and RNA [22-24]. It can be used for RNA sequencing [25] and in several applications where nucleic acid removal is desired, like reduction of the viscosity of a cell lysate, improvement of protein purification, and development of in vitro translation systems [26-28]. In S. aureus, Nuc participates in the spread of the bacterial cells in the infected host [29] as a naturally-secreted enzyme: cleavage of the precursor signal peptide leads to the secretion of the pro-peptide form (NucB) that is processed to the mature form (NucA) [30]. Different forms of Nuc protein have been produced in several species: the native wildtype form, in Bacillus subtilis [31], Corynebacterium glutamicum [32] and L. lactis [33], and recombinant forms fused to different signal peptides, in E. coli $[26,34]$ and in L. lactis $[16,35]$ where $\mathrm{NucB}$ processing to NucA was found to require HtrA protease $[3,36]$.

In this study, a recombinant Nuc form (rNuc) was successfully produced and secreted in L. lactis using a recently developed expression-secretion system [13] and small-scale pH-regulated reactors. An active rNuc protein could be purified in a single step from the culture medium, indicating that secretion is a good method for facilitating the purification of a heterologous protein produced in L. lactis.

\section{Results}

\section{Expression-secretion vector}

pGTP_FZ301 (Figure 1A) is an expression and secretion vector for L. lactis that is derived from pLB145 [13]. pGTP_FZ301 enables any ORF to be cloned as a translational fusion to the lactococcal sequence encoding Exp4 signal peptide $[15,16]$, and the fusion and zitR constitute an operon under the control of the $\mathrm{P}_{\mathrm{Zn}}$ promoter [12]. The cloning of $n u c B$ ORF (encoding $\mathrm{NucB}$ form) into pGTP_FZ301 resulted in pGTP_FZ301_NucB, and led to the production of a recombinant precursor that is secreted as rNuc (Figure 1B). This recombinant protein was designed because the wild-type Nuc precursor which bears an atypical signal peptide is not efficiently secreted in L. lactis [33], in contrast to a fusion between $\mathrm{NucB}$ and a lactococcal signal peptide [35].

\section{Optimization of induction conditions}

For rNuc production in L. lactis subsp cremoris strain 918 [MG1363(pGTP_FZ301_NucB)], a new medium was developed. This rich medium is free of animal compounds $(\mathrm{GM} 17 \mathrm{v})$, which could prove useful for the production of proteins that must be devoid of any potentially pathogenic contaminant, such as therapeutic proteins. In $\mathrm{pH}$-regulated cultures using GM17v, a final $\mathrm{OD}_{600}$ of 1516 could be reached (Figure 2).

The induction parameters of GM17v cultures were optimized taking previously published data about the lactococcal fermentation process [19] and induction conditions of ZitR-regulated $\mathrm{P}_{\mathrm{Zn}}$ in other media ([12] and data not shown) into account. Optimization was achieved using LacMF, a parallel fermentation control system able to monitor 12 mini-reactors simultaneously (Additional file 1, Figure S1). 


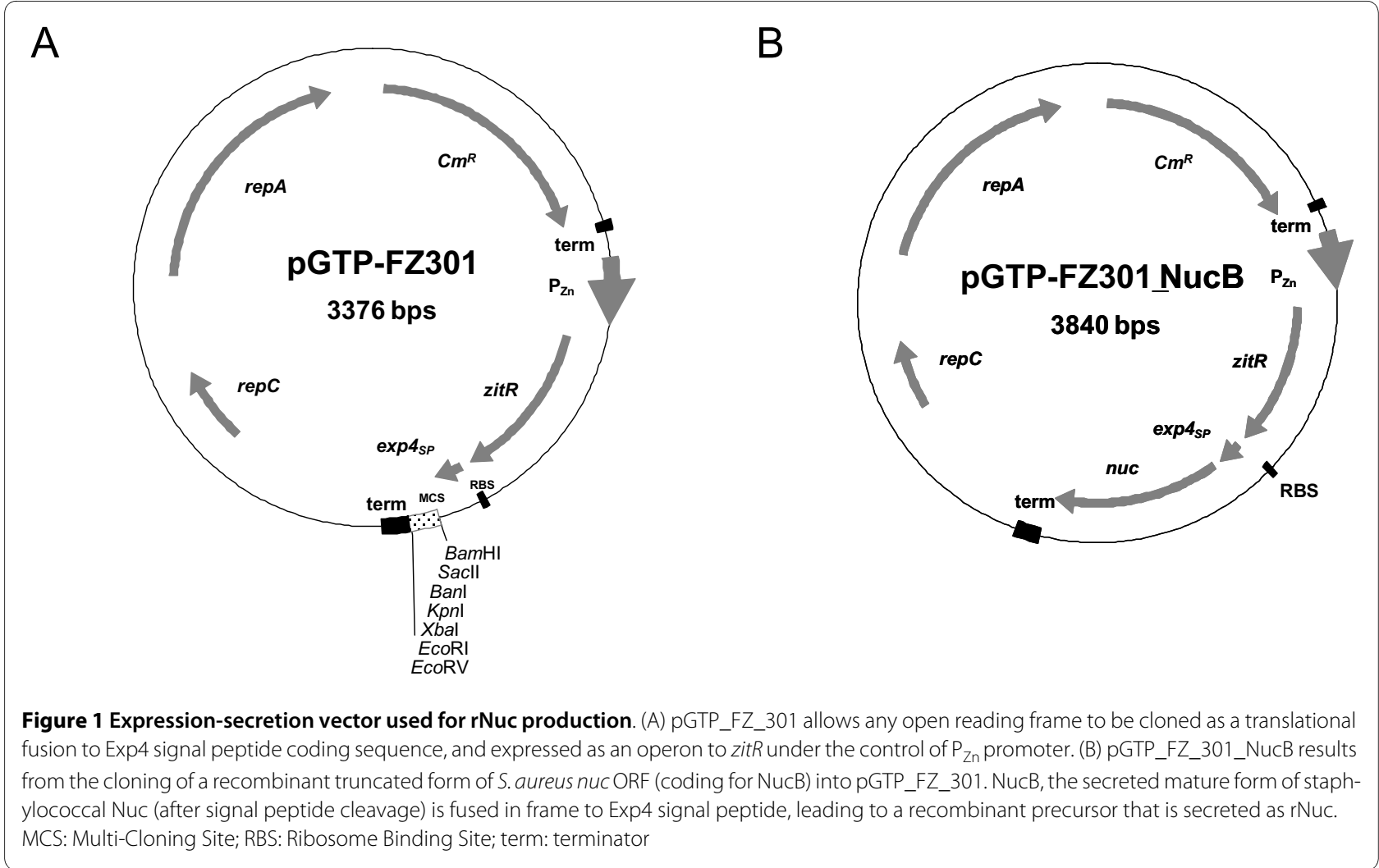

To determine the $\mathrm{P}_{\mathrm{Zn}}$ induction conditions in GM17v, different concentrations of the metal chelator EDTA were added to cultures in different growth phases. Both cell growth and rNuc secretion in the medium were monitored (Figure 2). Before induction, the rNuc protein was undetectable in mid-exponential phase cultures (for uninduced cells at an $\mathrm{OD}_{600}$ of 2 or 4, data not shown and Figures $2 \mathrm{~A}$ and $2 \mathrm{~B}$ ), and present in low amounts for lateexponential/stationary phase cultures $(5 \mathrm{mg} / \mathrm{L}$ for uninduced cells at an $\mathrm{OD}_{600}$ of 8, Figure $2 \mathrm{~A}$ ). This result suggested that the $\mathrm{P}_{\mathrm{Zn}}$ promoter was first repressed and then progressively induced during growth in GM17v medium, probably because extra-cellular $\mathrm{Zn}^{2+}$ became depleted, as previously observed in another rich medium, GM17 (data not shown), and in a chemically defined medium [12] (Daniel Llull, Olivier Son, Nicolas Trémillon, Sandrine Blanié, Julien Briffotaux, Sébastien Blugeon, Eric Morello, Hélène Rogniaux, Olivier Danot, and Isabelle Poquet: ZitR, a prototype of a new class of zinc responsive repressors in Streptococcaceae, submitted).

When added at $1 \mathrm{mM}$ at an $\mathrm{OD}_{600}$ of 2 (Figure $2 \mathrm{~A}$ ) or below (data not shown), EDTA impaired growth which stopped as early as one generation after addition. When 1 mM EDTA was added at an $\mathrm{OD}_{600}$ of 4 or 8 , the growth impairment seemed to be weaker, probably because late or post-exponential phase cells could almost reach the growth plateau after exposure to the inducer (Figure 2A).
The time of induction had a significant effect on the level of rNuc in the medium. Induction before the $\mathrm{OD}_{600}$ reached 2 severely impaired growth and consequently low rNuc levels were obtained (data not shown). In contrast, when EDTA was added at an $\mathrm{OD}_{600}$ of 2 or above, rNuc accumulated rapidly within the first hour of induction, and a high final level of between 100 and $200 \mathrm{mg} / \mathrm{L}$ was reached. The optimum of $200 \mathrm{mg} / \mathrm{L}$ was obtained for induction at $\mathrm{OD}_{600} 4$ (Figure $2 \mathrm{~A}$ ).

In a second phase of optimization, different concentrations of EDTA were added at an $\mathrm{OD}_{600}$ of 2 (Figure 2B). Whereas EDTA at $1 \mathrm{mM}$ (Figure 2A) or above (data not shown) severely impaired growth, little (a slightly reduced $\mathrm{OD}_{600}$ at the plateau) or no growth defect was observed for $500 \mu \mathrm{M}$ or $100 \mu \mathrm{M}$ EDTA (Figure 2B). rNuc production in the medium significantly varied with the inducer concentration. After induction with $100 \mu \mathrm{M}$ EDTA, the rNuc level followed growth and reached its maximum only at the growth plateau, whereas higher EDTA concentrations led a drastic rNuc accumulation within the first hour of induction (Figure 2B) followed by a slight further augmentation afterwards. Interestingly, the fast kinetics of accumulation was not related to a growth defect as it could be observed for either $500 \mu \mathrm{M}$ EDTA (Figure 2B) or $1 \mathrm{mM}$ EDTA (Figure 2A). $500 \mu \mathrm{M}$ was found to be the optimal inducer concentration when 


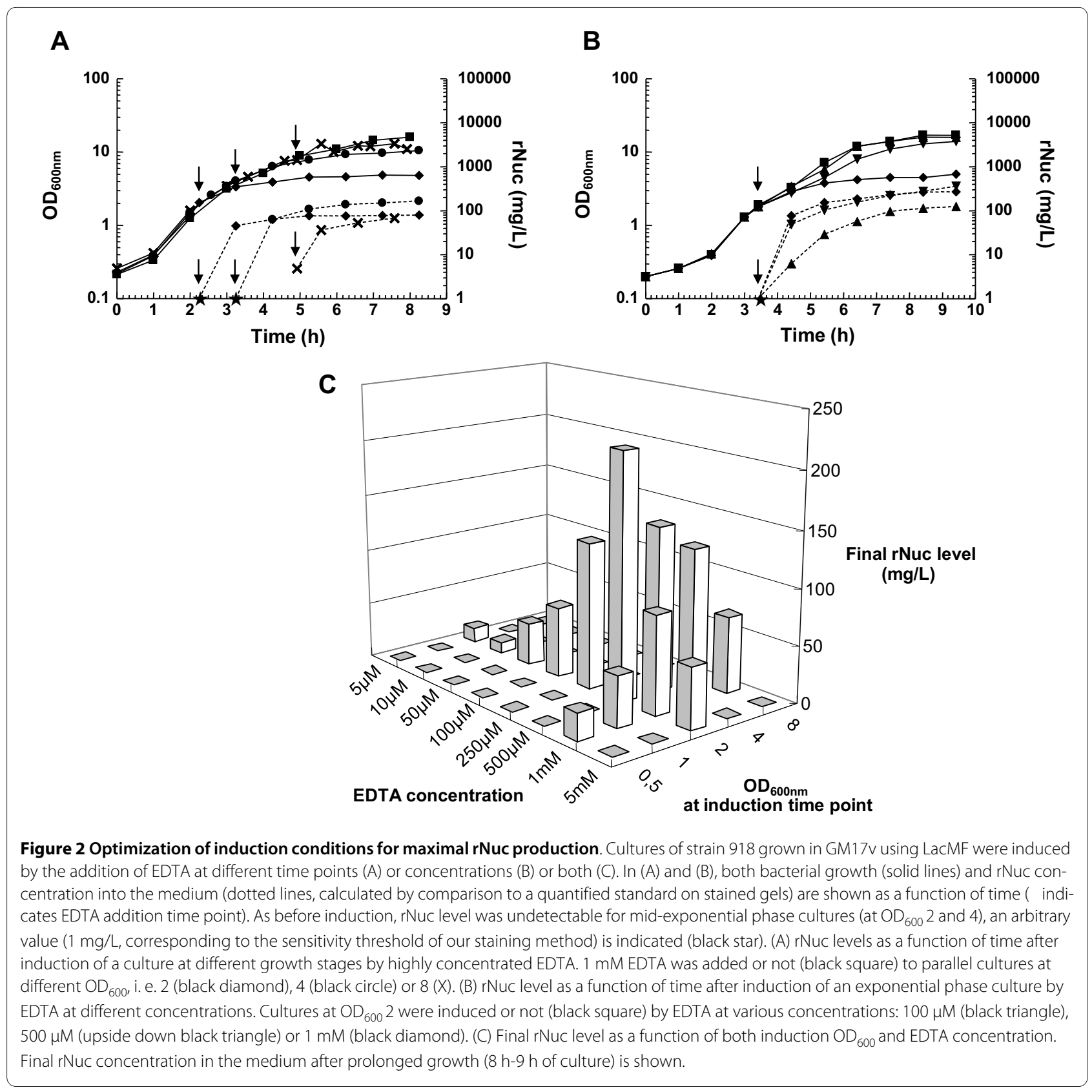

added at $\mathrm{OD}_{600} 2$ and allowed $\mathrm{rNuc}$ production to reach a level of $200 \mathrm{mg} / \mathrm{L}$.

As these results indicated that (i) both time of induction $\left(\mathrm{OD}_{600}\right)$ and EDTA concentration were important parameters for rNuc production, and that (ii) rNuc continued accumulating untill the growth plateau was reached (albeit sometimes slowly), the combined effect of both parameters on final rNuc levels after prolonged cultures was monitored (Figure 2C). rNuc increased in direct proportion to the EDTA concentration up to 500 $\mu \mathrm{M}$. Above $1 \mathrm{mM}$ EDTA, rNuc production did not improve regardless of the $\mathrm{OD}_{600}$ at which EDTA was added (Figure 2C). The maximal concentration of rNuc in the medium, $210 \mathrm{mg} / \mathrm{L}$, was obtained when $500 \mu \mathrm{M}$ EDTA was added to cells at an $\mathrm{OD}_{600}$ of 2 (Figures $2 \mathrm{~B}$ and $2 \mathrm{C})$, thus defining the optimal conditions for rNuc production and secretion in lactococcal cultures grown in GM17v.

In a second set of experiments, two media, the previously-used rich medium, GM17v, and a chemically defined medium, CDM [37], were compared. Interestingly, the induction conditions optimised for GM17v medium were applicable to CDM and allowed production of rNuc to comparable levels (Figure 3). 


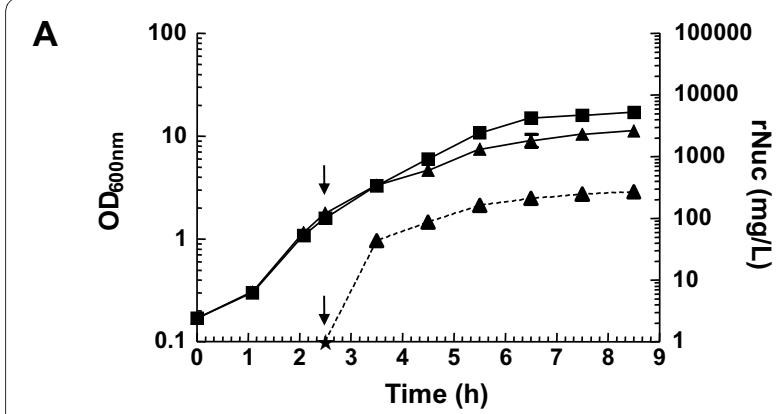

B

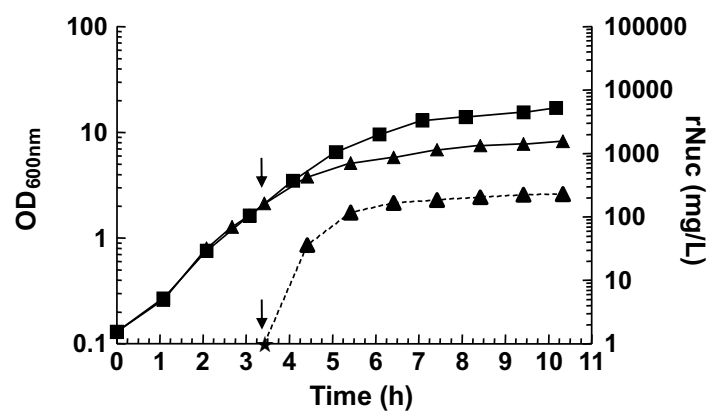

Figure 3 rNuc production as a function of the culture medium. Strain 918 was grown in either GM17v (A) or CDM (B) till an $\mathrm{OD}_{600}$ of 2, and induced or not (black square) by addition of $500 \mu \mathrm{M}$ EDTA (black triangle). Culture growth and rNuc concentration in the medium are indicated by solid or dotted lines respectively. The induction time point and undetectable levels of rNuc ( $<1 \mathrm{mg} / \mathrm{L}$, see Figure 2 Legend) are respectively indicated by and (black star) symbols.

\section{One-step Purification and nuclease activity}

rNuc produced and secreted by strain 918 at the highest level (after induction of cells grown in GM17v to an $\mathrm{OD}_{600}$ of 2 by $500 \mu \mathrm{M}$ EDTA) was purified from the culture medium using a simple, previously-described single step procedure [38]. This procedure, based on cation exchange chromatography, excludes Usp45, the main secreted lactococcal protein [7] (Figure 4). Approximately $85 \%$ of rNuc could be recovered from the culture supernatant by this method (data not shown), and finally, ultrapure rNuc (> 99\%) concentrated at $115 \mathrm{mg} / \mathrm{L}$ (as determined by SDS-PAGE analysis using Bovine Serum Albumin (BSA) as a standard) was obtained. Nuclease activity on denatured DNA was assayed as previously described [22,23], showing that purified rNuc exhibited a high specific enzymatic activity of $2000 \mathrm{U} / \mathrm{mg}$ (for comparison, this is 7-20 times higher than a marketed Nuc protein [39]).

\section{Discussion}

To determine the conditions for the use of L. lactis to produce a secreted heterologous protein, we chose the staphylococcal nuclease, a protein used in the field of biotechnology. This nucleic acid degrading enzyme can be used in several applications, particularly protein purification, by reducing the viscosity of a cell lysate $[26,27]$ and the nucleic acid contamination of the protein which, in the specific case of therapeutic proteins, is required by FDA to be less than $100 \mathrm{pg}$ per dose [40].

A new system for the production of recombinant proteins was developed. As a cell factory, we used L. lactis grown in either a new, rich and animal compound-free medium $(\mathrm{GM} 17 \mathrm{v})$ or a chemically defined medium (CDM). The heterologous ORF was cloned in pGTP_FZ301 vector under the control of $\mathrm{P}_{\mathrm{Zn}}$ and fused to the sequence encoding the Exp4 signal peptide, and its expression was induced by the chelator EDTA. The whole production-secretion system should be fully compatible with regulatory restrictions in bioproduction for human therapeutics, and the proteins produced with it should be considered as GRAS products. Alternatively, L. lactis grown in CDM medium might also be an interesting host system for specific amino acid labelling $\left(\mathrm{C}^{13}, \mathrm{~N}^{15}\right.$, selenomethionine or seleno-cysteine) and protein structural studies through NMR or X-Ray crystallography.

For cell growth, a $\mathrm{pH}$-regulated batch fermentation process was used. Using a parallel fermentation control system (LacMF), the $\mathrm{pH}$ value was maintained at the set point by the addition of a mild alkaline agent, $\mathrm{NH}_{4} \mathrm{OH}$. It was previously shown that $\mathrm{pH}$ neutralization leads to prolonged exponential growth of L. lactis and increases the final cell density about fivefold compared with $\mathrm{pH}$ unregulated batch culture fermentation $[17,19]$. Indeed, the biomass of $\mathrm{pH}$-regulated cultures reached high levels (final $\mathrm{OD}_{600}$ of around 15-16, Figures 2 and 3). $\mathrm{NH}_{4} \mathrm{OH}$ addition also maintains lactic acid in its dissociated lactate form which is less-toxic [41] even though at high concentrations, it also slows growth [42]. To further increase the productivity of the expression system used here, lactate $[43,44]$ should be continuously extracted using continuous perfusion [45] (unpublished results) and electro-dialysis (i. e. REED) [46]. The latter technology with lactococcal expression system P170, allowed to reach protein yields in the gram per liter range [47]. Medium composition could also be optimized, as the addition of nitrogen and carbon sources was previously found to significantly increase protein production in $L$. lactis grown in a rich medium [19].

LacMF was a useful tool to optimize EDTA induction in L. lactis. The best way to induce the $\mathrm{P}_{Z n}$ promoter was to add a non-toxic concentration of EDTA to an exponential phase culture, in agreement with what had previously been observed in another medium [12]. Induction in the exponential phase should maximize the effective production period before the stationary phase and toxic lactate accumulation. 
A

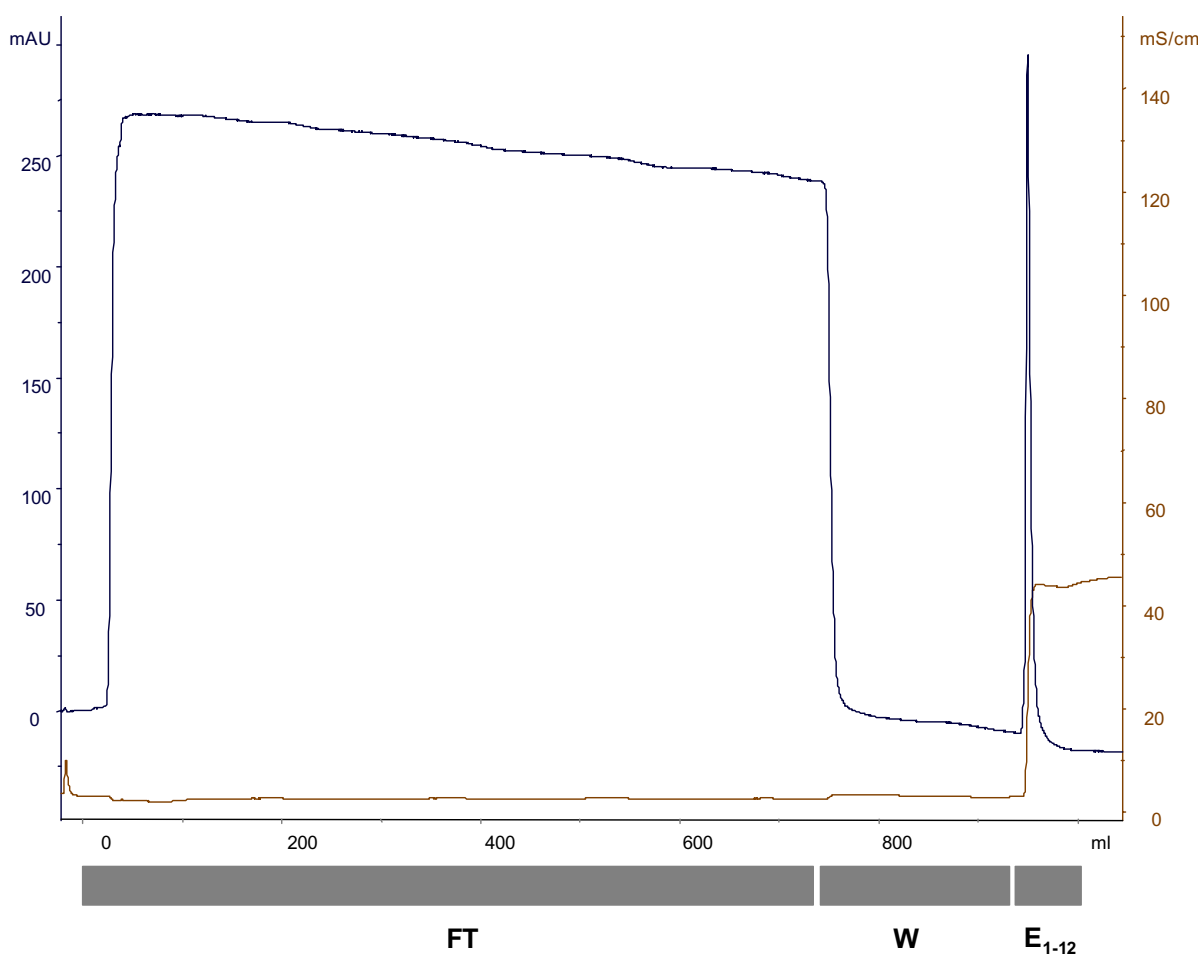

B

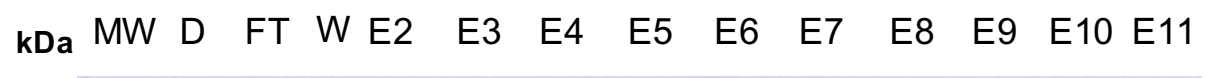

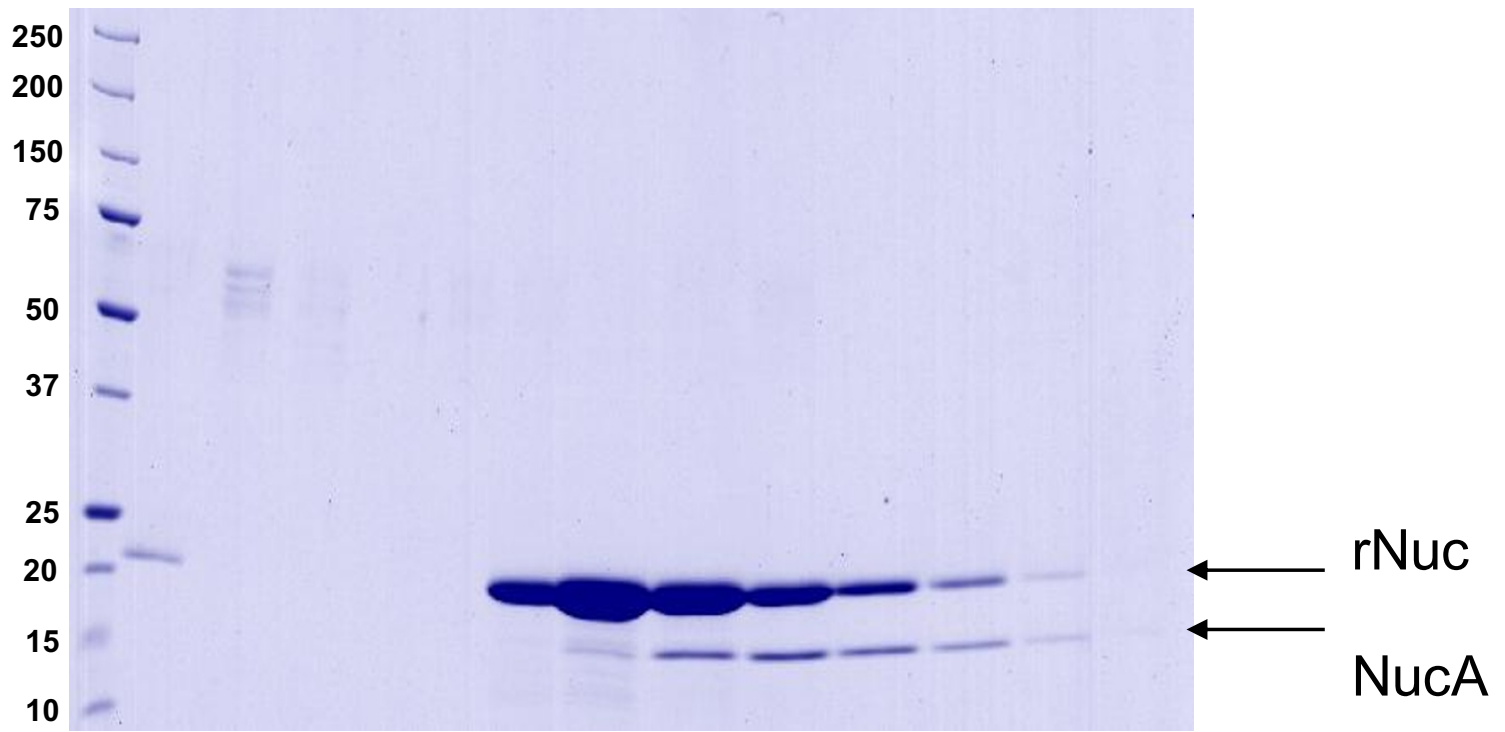

Figure 4 Purification of secreted rNuc protein by cationic exchange chromatography. (A) lon exchange chromatogram for rNuc purified from the supernatant of strain 918 grown in GM17v. NaCl concentration (brown line) and absorption at $280 \mathrm{~nm}$ (blue line) are shown. Fractions analysed by SDS-PAGE are indicated by grey bars underneath. (B) SDS-PAGE analysis of different fractions (E2-11) of the cationic exchange chromatography stained by Coomassie brilliant Blue. MW: Molecular Weight Marker, D: Diluted culture supernatant, FT: Flow Through, W: Washing, E1-12: Elution fractions number 1-12. Secreted rNuc protein (after signal peptide cleavage by signal peptidase) and the mature NucA form (resulting from pro-peptide processing by HtrA surface protease, as previously observed [3]), are indicated by arrows. 
In the absence of induction, rNuc is first undetectable when produced by exponentially growing cells, suggesting that its expression is repressed, and then weakly induced in late-exponential/stationary phase cells (Figures $2 \mathrm{~A}$ and $2 \mathrm{~B}$ ), as previously observed in another medium [12] (Daniel Llull, Olivier Son, Nicolas Trémillon, Sandrine Blanié, Julien Briffotaux, Sébastien Blugeon, Eric Morello, Hélène Rogniaux, Olivier Danot, and Isabelle Poquet: ZitR, a prototype of a new class of zinc responsive repressors in Streptococcaceae, submitted). This growth-phase dependent regulation suggests that free $\mathrm{Zn}^{2+}$, initially present in the medium at repression levels, could become exhausted or unavailable during growth, thus leading to progressive $\mathrm{P}_{\mathrm{Zn}}$ induction [12] (Daniel Llull, Olivier Son, Nicolas Trémillon, Sandrine Blanié, Julien Briffotaux, Sébastien Blugeon, Eric Morello, Hélène Rogniaux, Olivier Danot, and Isabelle Poquet: $\mathrm{ZitR}$, a prototype of a new class of zinc responsive repressors in Streptococcaceae, submitted). This could also explain the differences in rNuc accumulation kinetics according to the inducer concentration. When induced at high EDTA concentration (at and above $500 \mu \mathrm{M}$ ), rNuc rapidly accumulates (within $1 \mathrm{~h}$ ) almost to its maximal level, whereas at $100 \mu \mathrm{M}$ EDTA, accumulation is much slower and goes on for a longer time (Figure 2B). Interestingly, rNuc levels of exponentially growing cells induced by $100 \mu \mathrm{M}$ EDTA for $1 \mathrm{~h}$ (Figure 2B) and of uninduced cells at $\mathrm{OD}_{600}=8$ (Figure $2 \mathrm{~A}$ ) are similar, suggesting that $100 \mu \mathrm{M}$ EDTA only has a weak inducing effect, in agreement with the observation that it has only a slight, if any, effect on cell growth (Figure 2B). The final rNuc level after several hours of induction by $100 \mu \mathrm{M}$ EDTA (Figure 2B) might result from an increased production rate due to a higher biomass in a medium progressively depleted of $\mathrm{Zn}^{2+}$.

The EDTA concentration for optimal induction is significantly higher (more than 10 times) in both GM17v and CDM medium than in SA, the medium we previously used [12]. This is not surprising, as CDM and SA media are highly different, notably for their micro-nutrient composition (for example $\mathrm{Mn}^{2+}$ and $\mathrm{Cu}^{2+}$ are not added to $\mathrm{CDM}$ in contrast to SA), and in particular for $\mathrm{Zn}^{2+}$ content, which is much higher (3 orders of magnitude) in CDM than in SA $[37,48]$. Meanwhile, in both CDM and GM17v medium, the same optimal inducer concentration leads to a similar level of rNuc in the medium. As $\mathrm{P}_{\mathrm{Zn}}$ expression level was recently found to be inversely correlated to extra-cellular $\mathrm{Zn}^{2+}$ concentration (Daniel Llull, Olivier Son, Nicolas Trémillon, Sandrine Blanié, Julien Briffotaux, Sébastien Blugeon, Eric Morello, Hélène Rogniaux, Olivier Danot, and Isabelle Poquet: ZitR, a prototype of a new class of zinc responsive repressors in
Streptococcaceae, submitted), this indicated that GM17v and CDM media had similar $\mathrm{Zn}^{2+}$ contents.

Induction by EDTA at high concentration $(1 \mathrm{mM})$ in GM17v and CDM led to a growth defect of strain 918 (Figures 2A, 2B and 3A). However, this was not due to the toxicity of EDTA per se, because of chelation of divalent cations to detrimental levels and cell starvation, as $1 \mathrm{mM}$ EDTA specifically affected strain 918 but not the parental strain MG1363 (under identical conditions in the absence of antibiotic selection; data not shown). The specific growth defect of strain 918 thus seems to result from the presence of the pGTP_FZ301_NucB plasmid, and it is tempting to speculate that it could be due to the metabolic burden of secreted rNuc overproduction. In B. subtilis, a similar inducer-dependent growth defect has already been described for a strain over-expressing an heterologous secreted protein: it was associated to a secretion stress that was shown to lead to an adaptative cell response including the induction of the CssRS regulon [49-51]. This study should help define the conditions for hitherto unexamined secretion stress in L. lactis.

In this study, under optimal induction conditions, an rNuc production yield of $210 \mathrm{mg} / \mathrm{L}$ was reached. This yield is comparable to the ones previously obtained for staphylococcal nuclease forms produced in $\mathrm{pH}$-regulated fermentative cultures of L. lactis using inducible P170 promoter [52] or the constitutive $\mathrm{P}_{\text {usp } 45}$ promoter [38]. The efficiencies of the ZitR-regulated $\mathrm{P}_{\mathrm{Zn}}$ and NICE expression systems were found to be comparable under classical conditions [12]. All these comparisons indicate that pGTP_FZ301 is an efficient tool and a useful alternative expression-secretion system in L. lactis.

rNuc could be purified from a lactococcal culture medium in a single-step process. As L. lactis secretes few native proteins, heterologous protein secretion greatly simplifies downstream processing and purification. Indeed, after a single purification using cationic exchange resin, $85 \%$ of the rNuc protein was recovered pure at $99 \%$ and fully active. For comparison, the cytoplasmic recombinant form of lysostaphin produced in L. lactis using the NICE expression system was recovered to $80 \%$, and was only $90 \%$ pure after three steps of cation exchange chromatography [19]. Similarly, the staphylococcal nuclease $R$ produced by $E$. coli required two steps of metal chelating affinity chromatography to be purified from a cell extract [53].Thus secretion in L. lactis appears to simplify the downstream purification process.

\section{Conclusions}

This study for the first time describes the use of the promoter $\mathrm{P}_{\mathrm{Zn}}$ in $\mathrm{pH}$-regulated mini-reactors. Optimization of induction conditions for nuclease production was rapidly achieved with the use of the $\mathrm{pH}$ controller LacMF 
and allowed to reach a yield of $210 \mathrm{mg} / \mathrm{L}$. Nuclease produced by L. lactis was purified from the culture supernatant, providing a highly pure and active enzyme that should be useful for removing RNA and DNA from cell extracts. The fermentation, production and purification processes that were set up for the production of staphylococcal nuclease in L. lactis proved to be competitive, and they should be used in the future for different heterologous proteins, like proteins of therapeutical value.

\section{Methods}

\section{Bacterial strains and standard culture conditions}

E. coli NEB 5- $\alpha$ (New England Biolabs, Ipswich, MA) was grown at $37^{\circ} \mathrm{C}$ with $200-250 \mathrm{rpm}$ shaking in reconstituted Luria Bertani (LB) broth: $1 \%$ tryptone (Sigma, St Louis MO), 5\% yeast extract (Fluka, St Louis MO), $1 \% \mathrm{NaCl}$ (Fluka) resuspended in pure water, supplemented with ampicillin at $100 \mu \mathrm{g} / \mathrm{mL}$ (Sigma) when necessary. Solid media were prepared by adding technical agar (Invitrogen, Paisley UK) at a final concentration of $1.5 \% \mathrm{w} / \mathrm{v} . L$. lactis MG1363 strain [54] and strain 918 [i. e. MG1363(pGTP_FZ301_NucB)] were routinely grown at $30^{\circ} \mathrm{C}$ without shaking in rich M17 (Fluka) supplemented with $1 \%$ glucose and with chloramphenicol $5 \mu \mathrm{g} / \mathrm{mL}$ (Sigma) for plasmid selection in the case of strain 918.

\section{A parallel fermentation system able to monitor 12 mini- reactors}

LacMF (Additional file 1, Figure S1) is a proportional, integrative and derivative (PID) controller that allows continuous $\mathrm{pH}$ monitoring and control of 12 simultaneous mini-reactors of $50 \mathrm{~mL}-1 \mathrm{~L}$. $\mathrm{pH}$ is maintained at the set point by adding $30 \% \mathrm{v} / \mathrm{v} \mathrm{NH} \mathrm{NH}_{4} \mathrm{OH}$ (Fluka) to the different cultures, using a pump with twelve solenoid valves (Additional file 1, Figure S1) that open sequentially and for limited times. $\mathrm{NH}_{4} \mathrm{OH}$ neutralizes lactate produced by fermentation, thus impeding medium acidification and leading to prolonged exponential growth and a higher biomass. Cultures are maintained at $30^{\circ} \mathrm{C}$ and continuously homogeneized by a magnetic stirrer (with 100$150 \mathrm{rpm}$ agitation). LacMF system allowed optimization to be performed quickly, within two weeks and only 4 rounds of 12 independent experiments.

\section{Fermentation and induction conditions in mini-reactors}

Strain 918 was inoculated to an initial $\mathrm{OD}_{600}$ of 0.2 in 200 $\mathrm{mL}$ mini reactors and grown under standard fermentation conditions: at $30^{\circ} \mathrm{C}$ and $\mathrm{pH} 6.5$ using LacMF. Two different media: a chemically defined medium, CDM [37], or a rich medium free of animal compounds, GM17v, were used. GM17v contains $1 \%$ vegetable extract (Fluka), $0.25 \%$ yeast extract (Fluka), $0.05 \% \mathrm{~L}$-ascorbic acid (Sigma), 1.9\% Sodium glycero-phosphate (Sigma), 0.05\% $\mathrm{MgSO}_{4}$ (Fluka) and 5\% glucose. When necessary, EDTA $0.5 \mathrm{M} \mathrm{w} / \mathrm{v}$ (Sigma) was added to reach the indicated final concentrations and induce rNuc expression. Samples were harvested every hour to monitor bacterial growth by spectrophotometrically measuring absorbance at 600 nm.

\section{Plasmids}

Plasmids used in this study are listed in Table 1 and cloning strategy is shown in Figure 5. Sequence coding for Exp4 signal peptide $\left(\mathrm{SP}_{\text {Exp4 }}\right)$ was amplified from pLB145 [13] in a two-step PCR: using primers 1 and 2 (see Table 2 for primer sequences) for 5 cycles, and then primers 3 and 4 for 25 cycles. PCR product digested by RsrII and BamHI was cloned into pGTPb_102a cloning vector digested by the same enzymes, and the ligation was used to transform E. coli NEB 5- $\alpha$. pGTPb_SP $\mathrm{Exp}_{4}$ from an ampicillin resistant clone was verified by digestion and sequencing. $\mathrm{P}_{\mathrm{Zn}}$ zitR expression cassette was PCR-ampli-

Table 1: Plasmids used in this study.

\begin{tabular}{|c|c|c|}
\hline Name & Characteristics & Reference \\
\hline pLB145 & $\begin{array}{l}\mathrm{Cm}^{\mathrm{R}} \text {, pWV01 derivative carrying } \exp _{\mathrm{SP}}-n u c B \text { gene fusion under the control of ZitR-regulated } \\
\mathrm{P}_{\mathrm{Zn}} \text { promoter }\end{array}$ & {$[13]$} \\
\hline pGTPb_102a & $\begin{array}{l}\text { Amp }{ }^{R} \text {, pFastBacHta (Invitrogen Paisley UK) derivative carrying an ORF for HFFT tag (His Flag } \\
\text { FoldFold Flag Tev) [56-58] }\end{array}$ & This study \\
\hline pGTPb_SP ${ }_{\text {Exp4 }}$ & $\begin{array}{l}\text { Amp }{ }^{R}, p G T P b \_102 a \text { derivative where the ORF for Exp4 signal peptide }\left(\mathrm{SP}_{\text {Exp }_{4}}\right) \text { has been } \\
\text { cloned }\end{array}$ & This study \\
\hline pGTPb_P $\mathrm{Zn}_{\mathrm{n}} z i t R-\mathrm{SP}_{\mathrm{Exp} 4}$ & $\begin{array}{l}\text { Amp }{ }^{R}, p G T P b \_S P_{E x p 4} \text { derivative where } z i t R \text { is in operon with the ORF for } \mathrm{SP}_{\mathrm{Exp} 4} \text { under } \mathrm{P}_{\mathrm{Zn}} \\
\text { control }\end{array}$ & This study \\
\hline pGTP_FZ301 & $\begin{array}{l}\mathrm{Cm}^{\mathrm{R}}, \text { pLB145 derivative where a multi-cloning site has been cloned after the ORF for } \mathrm{SP}_{\text {Exp } 4} \\
\text { (in operon with zitR under } \mathrm{P}_{\mathrm{Zn}} \text { control) }\end{array}$ & This study \\
\hline pGTP_FZ301_NucB & $\begin{array}{l}\mathrm{Cm}^{\mathrm{R}} \text {, pGTP_FZ301 derivative where } n u C B \text { ORF has been cloned leading to a gene fusion } \\
\text { encoding } \mathrm{SP}_{\mathrm{Exp} 4}-\mathrm{NucB} \text { precursor and expressed under the control of ZitR-regulated } \mathrm{P}_{\mathrm{Zn}} \\
\text { promoter }\end{array}$ & This study \\
\hline
\end{tabular}


Table 2: Oligonucleotides used in this study.

\begin{tabular}{|c|c|}
\hline Name & Sequence \\
\hline 1 & 5' ACTCGGTCCGTACCTTAAGGAGATATAAAAATGA 3' \\
\hline 2 & $\begin{array}{l}\text { 5' TTITITGGATCCAAACCTGCCAGTATCATCAGCAAATACA } \\
\text { ACGGCT 3' }\end{array}$ \\
\hline 3 & 5' GAAAAAAACTCGGTCCGTACCTTAAGGAGA 3' \\
\hline 4 & 5' GTIITITIITGGATCCAAACCTGCCAGT 3' \\
\hline 5 & 5' GATATATATATGGTCCAGATCTITGATCAAGGATCTGTC 3' \\
\hline 6 & 5' TCCTTAAGGTACGGACCGTCTTCATCGAAACTCTTCAGT 3 \\
\hline 7 & 5' AAAATGATAACCATCTCGCAA 3' \\
\hline 8 & 5' CTACAAATGTGGTATGGCTGAT 3' \\
\hline 9 & 5' TTTAAATTTAGGATCCGCATCACAAACAGATAACGG 3' \\
\hline 10 & 5' TATATATATAGGTACCTTATTGACCTGAATCAGCGT 3' \\
\hline
\end{tabular}

fied from pLB145 using primers 5 and 6. PCR product digested by AvaII was cloned into pGTPb_102a_SP previously digested by RsrII and dephosphorylated. Ligation reaction was transformed into NEB 5- $\alpha$ competent cells. pGTPb_P $\mathrm{Zn}_{\mathrm{n}}$ zitR-SP $\mathrm{Exp}_{\mathrm{Ex}}$ from an ampicillin-resistant clone was verified by digestion and sequencing, revealing three silent mutations in zitR sequence. $\mathrm{P}_{\mathrm{Zn}}$ zitR $\mathrm{SP}_{\text {Exp4 }}$ expression and secretion cassette was PCR-amplified from pGTPb_P $\mathrm{P}_{\mathrm{Zn}}$ zitR-SP $\mathrm{Exp}_{\mathrm{E}}$ using primers 7 and 8. PCR product digested by BglII and EcoRI was ligated into pLB145 previously digested by the same enzymes, and the ligation was introduced into L. lactis MG1363 competent cells. pGTP_FZ301 from a chloramphenicol-resistant clone was verified by digestion and sequencing. $n u c B$ ORF that encodes the mature secreted part (NucB or proNuc) of staphylococcal nuclease after signal peptide cleavage [30] was PCR-amplified from pLB145 [13] using primers 9 and 10. PCR product was digested by BamHI and KpnI, cloned into pGTP_FZ301 previously digested by BamHI and KpnI, and ligation was used to transform MG1363. pGTP_FZ301_NucB plasmid extracted from a chloramphenicol resistant clone was verified by digestion and sequencing.

Restriction enzymes, T4 DNA ligase and Antartic phosphatase (New england Biolabs, Ipswich, MA), high fidelity Phusion $^{\mathrm{TM}}$ DNA polymerase (Finnzymes, Espoo, Finland) were used according to recommendations. DNA purification kits were purchased from Macherey-Nagel (Düren, Deutschland). Sequencing was performed by Genome express (Meylan, France).

\section{SDS-PAGE and protein quantification}

Supernatants were separated from cell samples by centrifugation and stored at $-20^{\circ} \mathrm{C}$. Protein samples were analysed by SDS-PAGE using gradient (7.5-16.8\%) gels and Precision Plus Protein Standards was used for molecular weight estimation (Biorad, California, USA). Commercial BSA (Sigma) was used as a standard for protein quantification. Gels were stained by Coomassie blue G250 (Biorad), scanned (GS800 Calibrated densitometer, Biorad) and analyzed using Image Quant (Amersham Biosciences, Uppsala Sweden).

\section{Nuclease purification}

Culture supernatant was filtrated on $0.22 \mu \mathrm{m}$ membrane, diluted 15-fold in ultrapure water and loaded on a $10 \mathrm{~mL}$ SP sepharose column (GE healthcare, Hillerod, Denmark). All purification steps were performed on an AKTA purifier (GE healthcare). Column was washed with 20 volumes of washing buffer $(15 \mathrm{mM}$ sodium phosphate buffer, $15 \mathrm{mM} \mathrm{NaCl}, \mathrm{pH}$ 7.5). Nuclease was eluted by 10 volumes of elution buffer I (15 mM sodium phosphate buffer, $500 \mathrm{mM} \mathrm{NaCl}, \mathrm{pH}$ 7.5) and automatically collected in fractions of $2.5 \mathrm{~mL}$ using FRAC910 (GE Healthcare). Elution fractions were checked by SDS-PAGE, pooled together and dialysed four times using a Spectra POR dialysis membrane with a cut-off of $3.5 \mathrm{kDa}$ (Spectrum, Rancho Dominguez, CA) against $500 \mathrm{~mL}$ of dialysis buffer (20 mM Tris buffer, $100 \mathrm{mM} \mathrm{NaCl}, 2 \mathrm{mM}$ EDTA, pH.7.5). Nuclease concentration was measured by densitometry and the purified protein was stored at $-20^{\circ} \mathrm{C}$ in storage buffer (10 mM Tris buffer,, $50 \mathrm{mM} \mathrm{NaCl}, 1 \mathrm{mM}$ EDTA, 50\% glycerol, pH 7.5).

\section{Nuclease assay}

Nuclease activity was assayed using a modified version of a previously described method [22]. $10 \mu \mathrm{L}$ of purified nuclease protein was incubated in $500 \mu \mathrm{L}$ of reaction buffer (25 mM Tris- $\mathrm{HCl}, 10 \mathrm{mM} \mathrm{CaCl}_{2}, 0.01 \% \mathrm{BSA}(\mathrm{w} / \mathrm{v})$, $0.1 \%$ Salmon sperm DNA pH 8.8) at $37^{\circ} \mathrm{C}$ for $30 \mathrm{~min}$, and the reaction was stopped by addition of $500 \mu \mathrm{L}$ of $4 \%$ (v/ v) perchloric acid and left for $15 \mathrm{~min}$ on ice. In negative controls, purified nuclease protein was added after the addition of perchloric acid. Acid-insoluble nucleic acids were sedimented by centrifugation for $10 \mathrm{~min}$ at $15000 \mathrm{~g}$ at $4^{\circ} \mathrm{C}$. DNA hydrolysis was determined by spectrophotometrically measuring the absorbance of acid soluble polynucleotides at $260 \mathrm{~nm}$ (One unit is defined as producing 1 $\mu$ mole of acid soluble polynucleotides from DNA per minute at $\mathrm{pH} 8.8$ and $37^{\circ} \mathrm{C}$ [55]).

\section{Additional material}

Additional file 1 LacMF, a parallel fermentation control system. 12 lactococcal cultures in mini-reactors of $200 \mathrm{~mL}$ can be made in parallel. They are maintained at $30^{\circ} \mathrm{C}$ and continously homogeneized by a magnetic stirrer ?), and $\mathrm{pH}$ is controlled by supplying a neutralizing agent, $\mathrm{NH}_{4} \mathrm{OH}$, via a proportional, integrative and derivative (PID) controller. $\mathrm{NH}_{4} \mathrm{OH}$ is added to the mini-reactors by a pump (?) with twelve solenoid valves (?). 


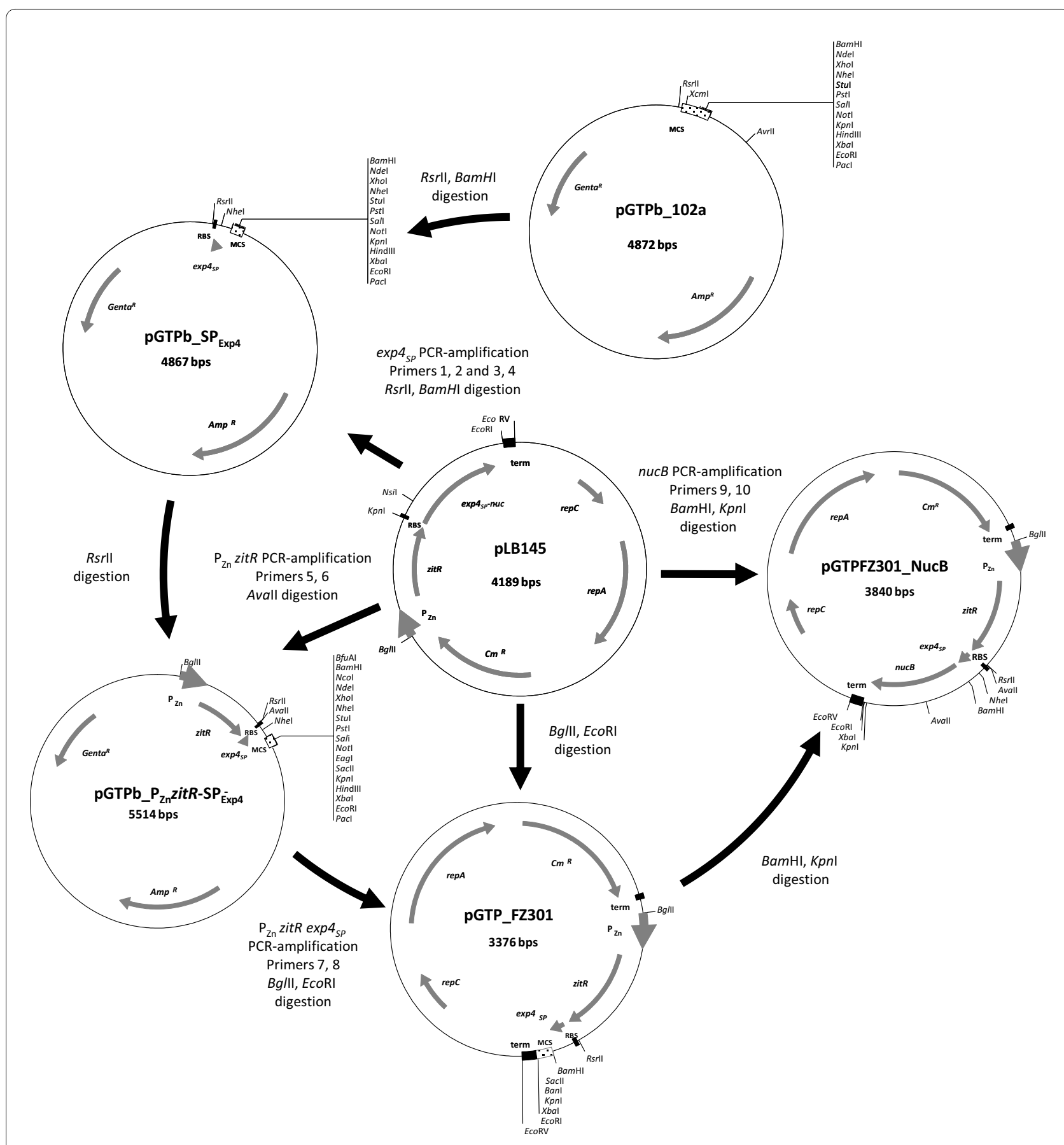

Figure $\mathbf{5}$ Cloning strategy. The construction of the various plasmids used in this study is shown (see the Plasmids paragraph in Methods section for further details).

\section{Competing interests}

The authors declare that they have no competing interests.

\section{Authors' contributions}

NT designed and supervised experiments and drafted the manuscript. NI initiated the experiments. JM and TD respectively supervised purification and fermentation experiments. $\mathrm{HG}, \mathrm{ED}$ and IP defined the strategy and supervised the project. HG and ED helped to draft manuscript, and IP edited the manuscript.
IP supervised the entire PhD project of NT. All authors read and approved the final manuscript.

\section{Acknowledgements}

NT was a recipient of a CIFRE grant between Ministère de l'Enseignement Supérieur et de la Recherche (Paris, France) via ANRT (Association Nationale de la Recherche et de la Technologie, Paris, France) and GTP Technology (Labège, France). We thank Constant Meunier, Corinne Bruand and Carinne Velasco from 
GTP-Technogy for excellent technical assistance. We are thankful to Maarten van de Guchte (Institut Micalis, INRA, Jouy-en-Josas, France) for critical reading of the manuscript.

\section{Author Details}

${ }^{1}$ GTP-Technology, Immeuble Biostep, BP 48184, 31681 Labège Cedex, France and 2INRA, UMR1319 Micalis (Microbiologie de l'Alimentation au service de la Santé), Domaine de Vilvert, Bâtiment 222, F-78352 Jouy-en-Josas cedex, France

Received: 3 June 2009 Accepted: 21 May 2010

Published: 21 May 2010

\section{References}

1. Le Loir Y, Azevedo V, Oliveira SC, Freitas DA, Miyoshi A, BermudezHumaran LG, Nouaille S, Ribeiro LA, Leclercq S, Gabriel JE, et al:: Protein secretion in Lactococcus lactis : an efficient way to increase the overall heterologous protein production. Microb Cell Fact 2005, 4(1):2.

2. Liu S, Tobias R, McClure S, Styba G, Shi Q, Jackowski G: Removal of endotoxin from recombinant protein preparations. Clin Biochem 1997, 30(6):455-463.

3. Poquet I, Saint V, Seznec E, Simoes N, Bolotin A, Gruss A: HtrA is the unique surface housekeeping protease in Lactococcus lactis and is required for natural protein processing. Mol Microbio/ 2000, 35(5):1042-1051.

4. Poquet I, Bolotin A, Sorokin A, Gruss A: Gram-positive bacteria deprived of HtrA proteasic activity and their uses. United States Patent 2006. US 6,994,997 B1

5. Murashima K, Chen CL, Kosugi A, Tamaru Y, Doi RH, Wong SL: Heterologous production of Clostridium cellulovorans engB, using protease-deficient Bacillus subtilis, and preparation of active recombinant cellulosomes. J Bacterio/ 2002, 184(1):76-81.

6. Kodama T, Endo K, Sawada K, Ara K, Ozaki K, Kakeshita H, Yamane K, Sekiguchi J: Bacillus subtilis AprX involved in degradation of a heterologous protein during the late stationary growth phase. J Biosci Bioeng 2007, 104(2):135-143.

7. van Asseldonk M, Rutten G, Oteman M, Siezen RJ, de Vos WM, Simons G: Cloning of usp45, a gene encoding a secreted protein from Lactococcus lactis subsp. lactis MG1363. Gene 1990, 95(1):155-160.

8. Mierau I, Leij P, van Swam I, Blommestein B, Floris E, Mond J, Smid EJ: Industrial-scale production and purification of a heterologous protein in Lactococcus lactis using the nisin-controlled gene expression system NICE: the case of lysostaphin. Microb Cell Fact 2005, 4:15.

9. Mierau I, Kleerebezem M: 10 years of the nisin-controlled gene expression system (NICE) in Lactococcus lactis. Appl Microbiol Biotechnol 2005, 68(6):705-717

10. Madsen SM, Arnau J, Vrang A, Givskov M, Israelsen H: Molecular characterization of the $\mathrm{pH}$-inducible and growth phase-dependent promoter P170 of Lactococcus lactis. Mol Microbio/ 1999, 32(1):75-87.

11. Madsen SM, Hindre T, Le Pennec JP, Israelsen H, Dufour A: Two acidinducible promoters from Lactococcus lactis require the cis-acting ACiD-box and the transcription regulator RcfB. Mol Microbiol 2005, 56(3):735-746

12. Llull D, Poquet I: New expression system tightly controlled by zinc availability in Lactococcus lactis. Appl Environ Microbiol 2004 70(9):5398-5406.

13. Morello E, Bermudez-Humaran LG, Llull D, Sole V, Miraglio N, Langella P, Poquet I: Lactococcus lactis, an efficient cell factory for recombinant protein production and secretion. J Mol Microbiol Biotechnol 2008, 14(13):48-58.

14. Poquet I, Llull D: Zinc-regulated prokaryotic expression cassettes. European Patent Office 2006, EP1537215

15. Bermudez-Humaran LG, Langella P, Cortes-Perez NG, Gruss A, TamezGuerra RS, Oliveira SC, Saucedo-Cardenas O, Montes de Oca-Luna R, Le Loir Y: Intranasal immunization with recombinant Lactococcus lactis secreting murine interleukin-12 enhances antigen-specific Th1 cytokine production. Infect Immun 2003, 71(4):1887-1896.

16. Poquet I, Ehrlich SD, Gruss A: An export-specific reporter designed for gram-positive bacteria: application to Lactococcus lactis. J Bacteriol 1998, 180(7):1904-1912.
17. Glenting J, Poulsen LK, Kato K, Madsen SM, Frokiaer H, Wendt C, Sorensen HW: Production of Recombinant Peanut Allergen Ara h 2 using Lactococcus lactis. Microb Cell Fact 2007, 6(1):28.

18. Ravn P, Arnau J, Madsen SM, Vrang A, Israelsen H: Optimization of signal peptide SP310 for heterologous protein production in Lactococcus lactis. Microbiology 2003, 149(Pt 8):2193-2201.

19. Mierau I, Olieman K, Mond J, Smid EJ: Optimization of the Lactococcus lactis nisin-controlled gene expression system NICE for industrial applications. Microb Cell Fact 2005, 4(1):16.

20. Cotton FA, Hazen EE Jr, Richardson DC: Crystalline extracellular nuclease of Staphylococcus aureus. J Bio/ Chem 1966, 241(19):4389-4390.

21. Hynes TR, Fox RO: The crystal structure of staphylococcal nuclease refined at $1.7 \AA$ Åsolution. Proteins 1991, 10(2):92-105.

22. Alexander $M$, Heppel $L A$, Hurwitz J: The purification and properties of micrococcal nuclease. J Biol Chem 1961, 236:3014-3019.

23. Cuatrecasas P, Fuchs S, Anfinsen CB: Catalytic properties and specificity of the extracellular nuclease of Staphylococcus aureus. J Biol Chem 1967, 242(7):1541-1547.

24. Heins JN, Suriano JR, Taniuchi H, Anfinsen CB: Characterization of a nuclease produced by Staphylococcus aureus. J Biol Chem 1967, 242(5):1016-1020.

25. Krupp G, Gross HJ: Rapid RNA sequencing: nucleases from Staphylococcus aureus and Neurospora crassa discriminate between uridine and cytidine. Nucleic Acids Res 1979, 6(11):3481-3490.

26. Cooke GD, Cranenburgh RM, Hanak JA, Ward JM: A modified Escherichia coli protein production strain expressing staphylococcal nuclease, capable of auto-hydrolysing host nucleic acid. J Biotechnol 2003, 101(3):229-239

27. Balasundaram B, Nesbeth D, Ward JM, Keshavarz-Moore E, Bracewell DG Step change in the efficiency of centrifugation through cell engineering: co-expression of Staphylococcal nuclease to reduce the viscosity of the bioprocess feedstock. Biotechnol Bioeng 2009, 104(1):134-142

28. Craig D, Howell MT, Gibbs CL, Hunt T, Jackson RJ: Plasmid cDNA-directed protein synthesis in a coupled eukaryotic in vitro transcriptiontranslation system. Nucleic Acids Res 1992, 20(19):4987-4995.

29. Sibbald MJ, Ziebandt AK, Engelmann S, Hecker M, de Jong A, Harmsen HJ, Raangs GC, Stokroos I, Arends JP, Dubois JY, et al:: Mapping the pathways to staphylococcal pathogenesis by comparative secretomics. Microbiol Mol Biol Rev 2006, 70(3):755-788.

30. Davis A, Moore IB, Parker DS, Taniuchi H: Nuclease B. A possible precursor of nuclease A, an extracellular nuclease of Staphylococcus aureus. J Biol Chem 1977, 252(18):6544-6553.

31. Miller JR, Kovacevic S, Veal LE: Secretion and processing of staphylococcal nuclease by Bacillus subtilis. J Bacterio/ 1987 169(8):3508-3514

32. Liebl W, Sinskey AJ, Schleifer KH: Expression, secretion, and processing of staphylococcal nuclease by Corynebacterium glutamicum. J Bacteriol 1992, 174(6):1854-1861.

33. Le Loir Y, Gruss A, Ehrlich SD, Langella P: A nine-residue synthetic propeptide enhances secretion efficiency of heterologous proteins in Lactococcus lactis. J Bacteriol 1998, 180(7):1895-1903.

34. Suciu D, Inouye M: The 19-residue pro-peptide of staphylococcal nuclease has a profound secretion-enhancing ability in Escherichia coli. Mol Microbiol 1996, 21(1):181-195.

35. Le Loir Y, Nouaille S, Commissaire J, Bretigny L, Gruss A, Langella P: Signal peptide and propeptide optimization for heterologous protein secretion in Lactococcus lactis. App/ Environ Microbio/ 2001, 67(9):4119-4127.

36. Miyoshi A, Poquet I, Azevedo V, Commissaire J, Bermudez-Humaran L, Domakova E, Le Loir Y, Oliveira SC, Gruss A, Langella P: Controlled production of stable heterologous proteins in Lactococcus lactis. Appl Environ Microbiol 2002, 68(6):3141-3146.

37. Cocaign-Bousquet MGC, Novak L, Lindley ND, Loublere P: Rational development of a simple synthetic medium for the sustained growth of Lactococcus lactis. Journal of Applied Microbiology 1995, 79(1):108-116.

38. Bodo E, Durieux A, Saint-Hubert C, Lavallée R, Boufflette JM, Simon JP: Recovery of Nuclease Produced by Lactococcus lactis Using Expanded Bed Ion Exchange Chromatography. Biotechnology Letters 2006, 28(13):1033-1039.

39. Nuclease micrococcal from Staphylococcus aureus 100-300 units/mg protein [http://www.sigmaaldrich.com/catalog/ 
40. Evolving scientific and regulatory perspectives on cell substrates for vaccine development [http://www.fda.gov/downloads/ BiologicsBloodVaccines/NewsEvents/WorkshopsMeetingsConferences/ TranscriptsMinutes/UCM056219.pdf]

41. Presser KA, Ratkowsky DA, Ross T: Modelling the growth rate of Escherichia coli as a function of $\mathrm{pH}$ and lactic acid concentration. Appl Environ Microbiol 1997, 63(6):2355-2360.

42. Boonmee M, Leksawasdi N, Bridge W, Rogers PL: Batch and continuous culture of Lactococcus lactis NZ133: experimental data and model development. Biochemical Engineering Journal 2003, 14(2):127-135.

43. Hofvendahl $\mathrm{K}$, Hahn-Hagerdal B: Factors affecting the fermentative lactic acid production from renewable resources (1). Enzyme Microb Technol 2000, 26(2-4):87-107.

44. Narayanan N, Roychoudhury P, Srivastava A: L (+) lactic acid fermentation and its product polymerization. Electronic Journal of Biotechnology 2004, 7(2):167-178.

45. Ohashi R, Yamamoto T, Suzuki T: Continuous production of lactic acid from molasses by perfusion culture of Lactococcus lactis using a stirred ceramic membrane reactor. J Biosci Bioeng 1999, 87(5):647-654.

46. Hongo M, Nomura Y, Iwahara M: Novel Method of Lactic Acid Production by Electrodialysis Fermentation. Appl Environ Microbiol 1986, 52(2):314-319.

47. Electro Membrane Technology Boosting Bioreactor Processes [http:// www.jurag.dk/docs/ISPE REED.pdf]

48. Jensen PR, Hammer K: Minimal Requirements for Exponential Growth of Lactococcus lactis. Appl Environ Microbiol 1993, 59(12):4363-4366.

49. Hyyrylainen $\mathrm{HL}$, Bolhuis $\mathrm{A}$, Darmon E, Muukkonen L, Koski P, Vitikainen M, Sarvas M, Pragai Z, Bron S, van Dij JM, et al:: A novel two-component regulatory system in Bacillus subtilis for the survival of severe secretion stress. Mol Microbiol 2001, 41(5):1159-1172.

50. Hyyrylainen $\mathrm{HL}$, Sarvas M, Kontinen VP: Transcriptome analysis of the secretion stress response of Bacillus subtilis. App/Microbiol Biotechnol 2005, 67(3):389-396.

51. Westers H, Westers L, Darmon E, van Dijl JM, Quax WJ, Zanen G: The CssRS two-component regulatory system controls a general secretion stress response in Bacillus subtilis. Febs J 2006, 273(16):3816-3827.

52. L. lactis process optimization [http://www.bioneer.dk/ index.php?pageid $=71]$

53. Yuanhe L, Zhaojie L, Guozhong J: Overexpression, purification of polyhis-nuclease $\mathrm{R}$ and its potential use. Biotechnology Techniques 1997, 11(10):729-732.

54. Gasson MJ: Plasmid complements of Streptococcus lactis NCDO 712 and other lactic streptococci after protoplast-induced curing. J Bacteriol 1983, 154(1):1-9.

55. Sulkowski E, Laskowski M: Phosphatase-free crystalline micrococcal nuclease. Journal of Biological Chemistry 1966, 241(19):4386-4388.

56. Hochuli E, Bannwarth W, Döbeli H, Gentz R, Stüber D: Genetic approach to facilitate purification of recombinant proteins with a novel metal chelate adsorbent. Bio/Technology 1988, 6(11):1321-1325.

57. Hopp TP, Prickett KS, Price VL, Libby RT, March CJ, Pat Cerretti D, Urdal DL, Conlon PJ: A short polypeptide marker sequence useful for recombinant protein identification and purification. Bio/Technology 1988, 6(10):1204-1210.

58. Kapust RB, Waugh DS: Controlled intracellular processing of fusion proteins by TEV protease. Protein expression and purification 2000, 19(2):312-318.

doi: 10.1186/1475-2859-9-37

Cite this article as: Trémillon et al., Production and purification of staphylococcal nuclease in Lactococcus lactis using a new expression-secretion system and a pH-regulated mini-reactor Microbial Cell Factories 2010, 9:37

\section{Submit your next manuscript to BioMed Central and take full advantage of:}

- Convenient online submission

- Thorough peer review

- No space constraints or color figure charges

- Immediate publication on acceptance

- Inclusion in PubMed, CAS, Scopus and Google Scholar

- Research which is freely available for redistribution

Submit your manuscript at www.biomedcentral.com/submit
C) BioMed Central 